\title{
Method for optimization of the orientation and fixing system of workpiece for the construction of control devices
}

\author{
Daniela-Monica Iordache*, Alin-Daniel Rizea, Aurel Costea, Eduard-Laurenţiu Niţu, and \\ Alexandru Babă \\ University of Piteşti, Manufacturing and Industrial Management Department, Târgu din Vale Street \\ No.1, Piteşti, Romania
}

\begin{abstract}
The development and evolution of technological equipment for machining, assembly and control ensure the modernization of manufacturing processes. Devices as subsystems of technological system in the general context of the development and diversification of machinery, tools, workpiece and drives are made in a variety of sizes and constructive variants that create difficulties in their structure and improvement. Part of the research in recent years presented in this paper have as major objectives the increase of accuracy, productivity and flexibility of orientation and fixing devices for control operations. To this end there have been developed a mathematical model, a new method of working and an algorithm for optimizing the construction of the orientation and fixing system of a new type of control device.
\end{abstract}

\section{Introduction}

Technology, originally defined as the science of methods and means of work and control or as a set of processes used to achieve a product, has evolved in the last 25 years by attempts to scientifically systematize knowledge and to develop correct methods of construction for modern technological systems.

Complex optimization of technological processes presented in specialized works [1-4] requires well-reasoned decisions in the field of technological equipment, implicitly in the field of device construction which justifies a systemic approach to manufacturing problems for highlighting the multitude of factors in their interdependencies.

The need to optimize the activities of the stages of design, production and exploitation [1-5] requires an objective analysis of the technological processes in which the orientation and fixing device of the workpiece is a component of the system that also includes technical, technological components and human factor.

The research and achievements in recent years have had as major objectives to improve performance and flexibility of processing, assembling or control equipment, in general, and of device, in particular.

${ }^{*}$ Corresponding author: monica.iordache@upit.ro 
The aim of this paper is to present original contributions of the authors on developing a mathematical model and a method of optimizing the orientation and fixing scheme of workpiece for the construction of work and control devices.

\section{The device in the operational technological system}

The device is considered in literature $[1,2,6,7]$ a subsystem of a technological system, which constitutes a unit in terms of technology, construction and functionality, which establishes and maintains the orientation of workspiece or tools, with the possibility to take over functions of machine-tool or operator.

Although there are a wide variety of constructive devices, determined by the multiple functions they perform, regardless of their type, having several common elements, the role of orientation being the most important.

In the design phase, the two categories of problems requiring a solution are:

- the theoretical study to establish the optimal orientation and fixing scheme of the semiproduct;

- the organological study to establish the optimal variant of construction for the orientation and fixing device of the workpiece.

\section{Methodology to optimize the orientation and fixing system of the workpiece}

In the field of machine construction it is frequently noted that the interest to apply in industry optimal solutions did not develop enough because it appeals exclusively to the experience of designers and the problem of optimizing complex processes and technological equipment is not a simple one $[1-4,6,8]$. Devices in general, but especially those for orientation and fixing workpiece, have recorded the lowest progress as compared to other subsystems, due to their constructive diversity $[1-3,6]$.

\subsection{Method to optimize the orientation and fixing system of workpiece to build devices}

According to the general theory of systems, the technologist is an analyst of the technological system, well-informed on the components of this system, who sets the solution to orient and fix the workpiece.

Figure 1 presents a new method to optimize the orientation and fixing system of workpiece, by which is obtained the optimal orientation and fixing scheme (SOF-O), expressed through informational symbolization.

The general algorithm to design - optimize SOF-O involves the following steps:

$\mathrm{E}_{01}$ - Chart of the operation with simplified drawing, data and information from $\mathrm{PO}$ and detail or assembly drawing;

$\mathrm{E}_{02}$ - Identifying explicit and implicit quotas and conditions required in the operation analyzed;

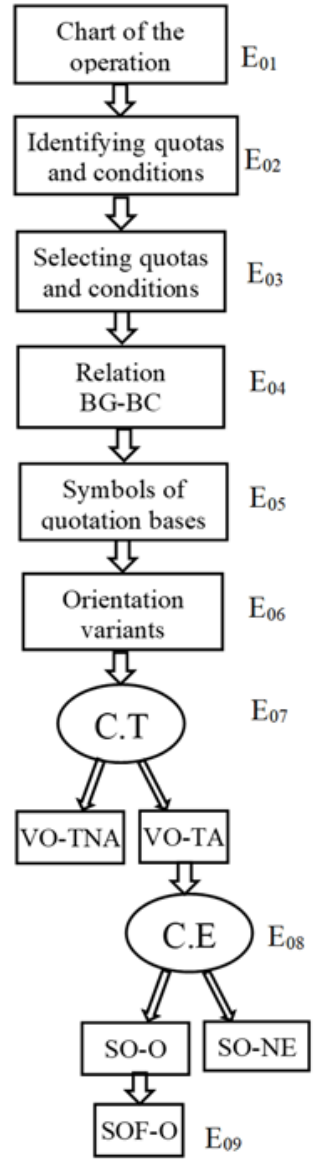

Fig. 1. Optimization scheme. 
$\mathrm{E}_{03}$ - Selecting quotas and conditions according to specified criteria;

$\mathrm{E}_{04}$ - Establishing the relation of dependency between the bases of generation (measurement) and those of quotation;

$\mathrm{E}_{05}$ - Symbols of quotation bases;

$\mathrm{E}_{06}$ - Establishing technically possible orientation variants (VO-TP);

$\mathrm{E}_{07}$ - Application of the technical selection criterion (error calculation) abiding by the condition Eor $<$ Eoa ;

$\mathrm{E}_{08}$ - Application of the economic selection criterion to obtain optimal orientation scheme (SO-O) ;

$\mathrm{E}_{09}$ - Choosing the fixing system to establish the optimal orientation and fixing scheme (SOF$\mathrm{O})$.

\subsection{Establishing technically possible orientation variants (VO-TP)}

\section{E01 Chart of the operation}

On the simplified drawing of the part to control (or process) a system of axes XYZ is associated, the quotas and conditions to be controlled (or carried out) in the analyzed operation are given, the surfaces of the part (processed or unprocessed) are numbered, previously processed surfaces are marked with a continuous thick line and will be controlled or processed with an interrupted thick line; the other surfaces are drawn with a thin line.

Figure 2 presents the chart of the control operation for the assembly water pump, as a complex case study to establish the optimal orientation and fixing scheme (SOF-O). Checking the quotas and conditions in this case is difficult because some processed surfaces are assembled with other parts (shaft and turbine) and the other ones will be partially covered by elements of the orientation system.
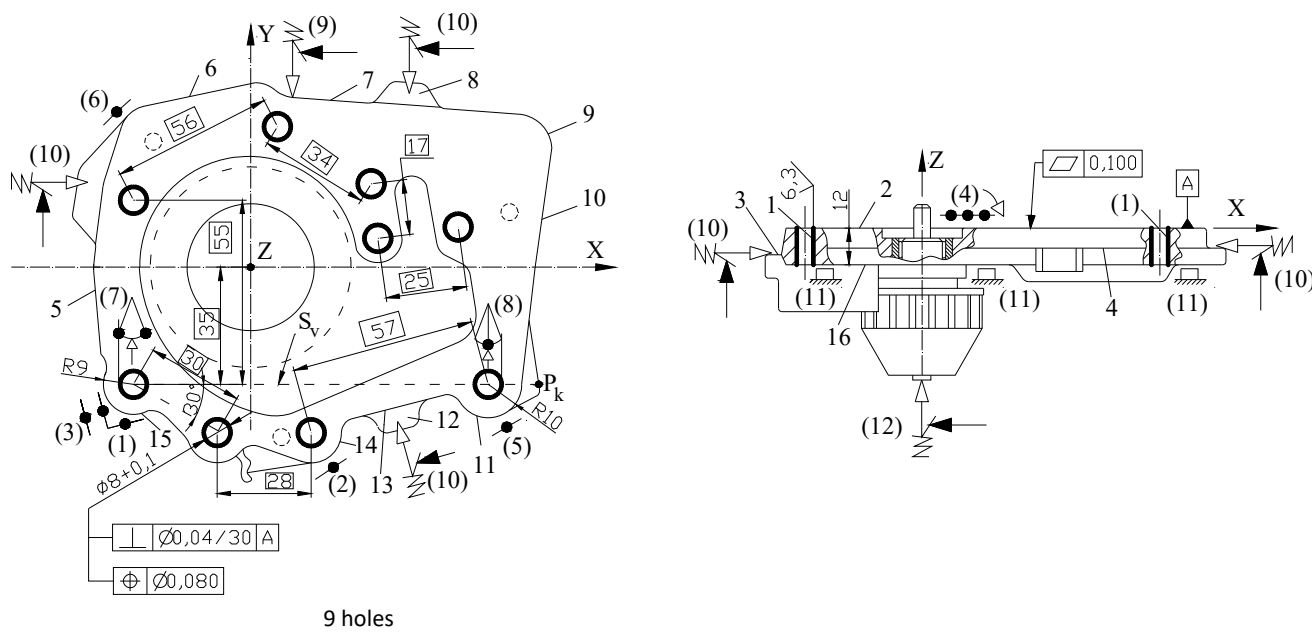

Fig. 2. Chart of the operation.

\section{E02 Identifying the quotas and conditions imposed by the analysed operation}

In Table 1 are specified the explicit or implicit quotas and conditions for the analyzed operation, the measuring or generating bases and quotation bases. Notations used refer to geometric elements of flat surface (S), right (D) and point (P).

E03 Selecting important and necessary quotas and conditions related to the orientation of the workpiece 
The quotas and conditions are analyzed and value 0 is assigned to conditions that are not related to the orientation of the semi-product and value 1 to those conditions that are linked to its orientation.

When there are two conditions that express the same thing, the condition which includes the other one is maintained.

Table 1. Quotas and conditions.

\begin{tabular}{|c|c|c|c|}
\hline $\begin{array}{c}\text { Quotas and } \\
\text { conditions to carry }\end{array}$ & $\begin{array}{c}\text { Measuring or } \\
\text { generating bases }\end{array}$ & $\begin{array}{c}\text { Quotation } \\
\text { bases }\end{array}$ & Observations \\
\hline $\mathrm{C}_{1}-\varnothing 8^{+0.1}$ & $\mathrm{Dz} \mathrm{z}_{1}-\mathrm{z}_{1}$ & - & \\
\hline $\mathrm{C}_{2}-30$ & $\mathrm{Dz} \mathrm{z}_{1}-\mathrm{z}_{1}$ & $\mathrm{Dz}_{1}-\mathrm{Z}_{1}$ & Notation $\mathrm{Dz}_{1}-\mathrm{z}_{1}$, is read: \\
\hline $\mathrm{C}_{3}-\mathrm{R} 9$ & $\mathrm{Dz}_{1}-\mathrm{z}_{1}$ & $\mathrm{Dz}_{15}-\mathrm{Z}_{15}$ & D - right \\
\hline $\mathrm{C}_{4}-28$ & $\mathrm{Dz}-\mathrm{z}_{1}$ & $\mathrm{Dz}_{1}-\mathrm{Z}_{1}$ & $\mathrm{z}-\mathrm{z}$, is the direction of axis $\mathrm{z}$; \\
\hline $\mathrm{C}_{5}-57$ & $\mathrm{Dz}_{1}-\mathrm{z}_{1}$ & $\mathrm{Dz}_{1}-\mathrm{z}_{1}$ & 1- refers to surface 1 (noted on \\
\hline $\mathrm{C}_{6}-55$ & $\mathrm{Dz} \mathrm{z}_{1}-\mathrm{z}_{1}$ & $\mathrm{Dz}_{1}-\mathrm{z}_{1}$ & the operation chart). \\
\hline $\mathrm{C}_{7}-56$ & $\mathrm{Dz}_{1}-\mathrm{z}_{1}$ & $\mathrm{Dz}_{1}-\mathrm{z}_{1}$ & Notation $\mathrm{S}_{2}$ is read: \\
\hline $\mathrm{C}_{8}-34$ & $\mathrm{Dz} \mathrm{z}_{1}-\mathrm{z}_{1}$ & $\mathrm{Dz}_{1}-\mathrm{Z}_{1}$ & $\mathrm{~S}$ - is a flat surface; \\
\hline $\mathrm{C}_{9}-17$ & $\mathrm{Dz}_{1}-\mathrm{z}_{1}$ & $\mathrm{Dz}_{1}-\mathrm{z}_{1}$ & 2- refers to surface 2 . \\
\hline $\mathrm{C}_{10}-25$ & $\mathrm{Dz}_{1}-\mathrm{z}_{1}$ & $\mathrm{Dz} \mathrm{z}_{1}-\mathrm{Z}_{1}$ & For $S_{V}$, it is understood that it is \\
\hline $\mathrm{C}_{11}-\perp$ & $\mathrm{Dz}_{1}-\mathrm{z}_{1}$ & $\mathrm{~S}_{2}$ & the imaginary (implicit) plane \\
\hline $\mathrm{C}_{12}-\overline{\mathrm{R} 10}$ & $\mathrm{Dz}_{1}-\mathrm{z}_{1}$ & $\mathrm{~S}_{\mathrm{V}}$ & passing through axes $\mathrm{D}_{\mathrm{Z} 1-\mathrm{Z} 1}$ of \\
\hline $\mathrm{C}_{13}-/ /$ & $\mathrm{Dz}_{1}-\mathrm{z}_{1}$ & $\mathrm{Dz}_{1}-\mathrm{Z}_{1}$ & the two holes in bosses R9 and \\
\hline $\mathrm{C}_{14}-\longrightarrow$ & $\mathrm{S}_{2}$ & $\mathrm{~S}_{2}$ & R10. \\
\hline $\mathrm{C}_{15}-12$ & $\mathrm{~S}_{2}$ & $\mathrm{~S}_{2}-\mathrm{S}_{16}$ & \\
\hline
\end{tabular}

If there are two contradictory conditions for a generating basis, the condition involving greater accuracy is maintained. According to these criteria the values are: $\mathrm{C} 1=0 ; \mathrm{C} 2=0 ; \mathrm{C} 3=1$; $\mathrm{C} 4=0 ; \mathrm{C} 5=0 ; \mathrm{C} 6=0 ; \mathrm{C} 7=0 ; \mathrm{C} 8=0 ; \mathrm{C} 9=0 ; \mathrm{C} 10=0 ; \mathrm{C} 11=1 ; \mathrm{C} 12=1 ; \mathrm{C} 13=0$ (is included in $\mathrm{C} 11$ ); $\mathrm{C} 14=1 ; \mathrm{C} 15=0$.

If the multitude of conditions imposed to the operation analysed is expressed as a product of a line matrix with the assigned values and a column matrix with the notations of conditions, a line matrix with the important and necessary conditions linked to the orientation of the workpiece is obtained.

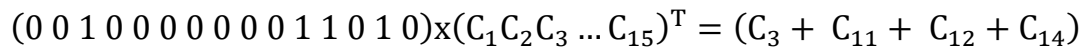

E04 Establishing the relation of dependency between measuring (generating) bases and those of quotation (obtaining quotation bases)

Conditions $\mathrm{C}_{3}, \mathrm{C}_{11}, \mathrm{C}_{12}, \mathrm{C}_{14}$ refer to the dependency of the generating bases (BG) and quotation bases $(\mathrm{BC})$, which can be expressed by relation: $\mathrm{R}(\mathrm{BG}, \mathrm{BC})$, formulated as a function of the form:

$$
\mathrm{Y}=\mathrm{f}(\mathrm{X}) \cdot \mathrm{W}
$$

where Y-generating basis; X-conditioning elements; W- quotation basis.

The relation adapted for this relation is:

$$
\operatorname{Ebg}=\mathrm{f}(\mathrm{cc}) \cdot \mathrm{Ebc}
$$

where: Ebg - elements of generation; $\mathrm{f}(\mathrm{cc})$ - function of quotas and conditions; Ebc elements of quotation bases.

By customizing of the relations (2) and (3) for the analyzed case, there are obtain: $C_{3}, D z_{1}-z_{1}=f(R 9) \cdot D z_{15}-Z_{15}$ 
$\mathrm{C}_{11}, \mathrm{Dz}_{1}-\mathrm{Z}_{1}=\mathrm{f}(\perp) \cdot \mathrm{S}_{2}$

$\mathrm{C}_{12}, \mathrm{Dz}_{1}-\mathrm{z}_{1}=\mathrm{f}(\mathrm{R} 10) \cdot \mathrm{S}_{\mathrm{V}}$

$\mathrm{C}_{14}, \mathrm{~S}_{2}=\mathrm{f}(/) \cdot \mathrm{S}_{2}$

$\mathrm{Dz} \mathrm{z}_{1}-\mathrm{Z}_{1}$, is the axis of the hole (holes) $\varnothing 8^{+0.1}$;

$\mathrm{S}_{2}$ is the stretched flat surface 2;

$\mathrm{Dz}_{15}-\mathrm{Z}_{15}$ is the axis of the surface $\mathrm{S} 9$;

$\mathrm{Sv}$ is the imaginary plane (implicit) passing through axis;

$D z_{1}-z_{1}$ and axis $D z_{1}-z_{1}$ of surface $\mathrm{R} 10$.

All these elements must be explicit, real and palpable.

Plane Sv, imaginary, will be made explicit by axis $\mathrm{Dz}_{15}-\mathrm{Z}_{15}$ and a fixed point $\mathrm{P}_{\mathrm{k}}$ which have a real correspondent on the workpiece.

Therefore it can be written:

$$
D z_{1}-Z_{1}=f(R 9) \cdot D z_{15}-Z_{15}+f(\perp) \cdot S_{2}+f(R 10) \cdot D z_{15}-Z_{15} / P_{k}+f(\square) \cdot S_{2}
$$

In its general form the relation becomes:

$$
\mathrm{Dz}_{1}-\mathrm{Z}_{1}=\mathrm{f}(\mathrm{R} 9, \perp, \mathrm{R} 10, \square) \cdot\left(\mathrm{Dz}_{15}-\mathrm{Z}_{15}, \mathrm{~S}_{2}, \mathrm{P}_{\mathrm{k}}\right)
$$

The elements of the quotation bases are:

$$
\operatorname{Ebc}\left\{\mathrm{Dz}_{15}-\mathrm{Z}_{15}, \mathrm{~S}_{2}, \mathrm{P}_{\mathrm{k}}\right\}
$$

where: $\mathrm{BC}_{\mathrm{I}}-\left(\mathrm{Dz}_{15}-\mathrm{Z}_{15}\right) ; \mathrm{BC}_{\mathrm{II}}-\left(\mathrm{S}_{2}\right) ; \mathrm{BC}_{\mathrm{III}}-\left(\mathrm{P}_{\mathrm{k}}\right)$

\section{E05 Symbolization of quotation bases}

Using informational symbolization, on the operation chart will be attached the icons that materialize the quotation bases:

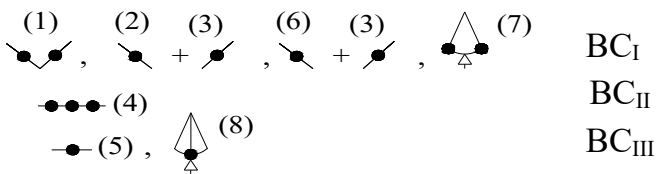

\section{E06 Establishing technically possible orientation variants (VO-TP)}

To establish technically possible orientation variants (VO-TP), condition of taking up to six degrees of freedom is:

$$
\begin{gathered}
\mathrm{A}_{1}\left(\mathrm{a}_{1}, \mathrm{a}_{2}, \ldots \mathrm{a}_{\mathrm{m} 1}\right) \\
\mathrm{A}_{2}\left(\mathrm{~b}_{1}, \mathrm{~b}_{2}, \ldots \mathrm{b}_{\mathrm{m} 2}\right) \\
\ldots \\
\mathrm{A}_{\mathrm{n}}\left(\mathrm{l}_{1}, \mathrm{l}_{2}, \ldots \mathrm{l}_{\mathrm{mn}}\right),
\end{gathered}
$$

where:

$A_{1}$ - the set of symbols for the first quotation basis;

$\mathrm{A}_{2}$ - the set of symbols for the second quotation basis;

$A_{n}$ - the set of symbols for the last quotation basis.

To generate all orientation variants it will be used the cartesian multiplication of sets $A_{1}$, $\mathrm{A}_{2}, \ldots \mathrm{A}_{\mathrm{n}}$ :

$$
\mathrm{A}_{1} \times \mathrm{A}_{2} \times \ldots \times \mathrm{A}_{\mathrm{n}}=\left\{\left(\mathrm{a}_{1}, \mathrm{~b}_{1} \ldots \mathrm{l}_{1}\right) ;\left(\mathrm{a}_{1}, \mathrm{~b}_{1} \ldots \mathrm{l}_{2}\right) ; \ldots\left(\mathrm{a}_{\mathrm{m} 1}, \mathrm{~b}_{\mathrm{m} 2} \ldots \mathrm{l}_{\mathrm{mn}}\right)\right\}
$$

For the analyzed set, the combination of symbols of orientation variants is:

$$
\begin{array}{ll}
\mathrm{V}_{\mathrm{I}}-(1)+(4)+(5) ; & \mathrm{V}_{\mathrm{II}}-(1)+(4)+(8) ; \\
\mathrm{V}_{\mathrm{III}}-(2+3)+(4)+(5) ; & \mathrm{V}_{\mathrm{IV}}-(2+3)+(4)+(8)
\end{array}
$$




$$
\begin{array}{ll}
\mathrm{V}_{\mathrm{V}}-(6+3)+(4)+(5) ; & \mathrm{V}_{\mathrm{VI}}-(6+3)+(4)+(8) \\
\mathrm{V}_{\mathrm{VII}}-(7)+(4)+(5) ; & \mathrm{V}_{\mathrm{VIII}}-(7)+(4)+(8)
\end{array}
$$

In order to check the maximum number of degrees of freedom cancelled, a matrix will be conceived based on calculation, by entering the number of degrees of freedom cancelled for the symbols belonging to the variants:

$$
\begin{aligned}
& \mathrm{V}_{\mathrm{I}} \\
& \mathrm{V}_{\mathrm{II}} \\
& \mathrm{V}_{\mathrm{III}} \\
& \mathrm{V}_{\mathrm{IV}} \\
& \mathrm{V}_{\mathrm{V}} \\
& \mathrm{V}_{\mathrm{VI}} \\
& \mathrm{V}_{\mathrm{VII}} \\
& \mathrm{V}_{\mathrm{VIII}}
\end{aligned} \quad\left(\begin{array}{lll}
2 & 3 & 1 \\
2 & 3 & 1 \\
2 & 3 & 1 \\
2 & 3 & 1 \\
2 & 3 & 1 \\
2 & 3 & 1 \\
2 & 3 & 1 \\
2 & 3 & 1
\end{array}\right)\left(\begin{array}{l}
1 \\
1 \\
1
\end{array}\right)=\left(\begin{array}{l}
2+3+1 \\
2+3+1 \\
2+3+1 \\
2+3+1 \\
2+3+1 \\
2+3+1 \\
2+3+1 \\
2+3+1
\end{array}\right)=\left(\begin{array}{l}
6 \\
6 \\
6 \\
6 \\
6 \\
6 \\
6 \\
6
\end{array}\right)
$$

All variants meet the condition imposed and become technically possible orientation variants (VO-TP).

\section{E07 Application of the technical selection criterion (CT)}

For the analysis of the orientation accuracy of technically possible variants (VO-TP): it has to be calculated the allowable orientation error $\left(\varepsilon_{\mathrm{oa}}\right)$; the real orientation error $\left(\varepsilon_{\mathrm{or}}\right)$; checking at the end the accuracy of variants by condition $\varepsilon_{\text {or }}<\varepsilon_{\text {oa }}$.

Allowable orientation errors $\left(\mathcal{E}_{\mathrm{oa}}\right)$ are determined by relation $[1,3,5,8,9]$ :

$$
\varepsilon_{o a}=\left(\frac{1}{5} \cdots \frac{1}{10}\right) T_{P}
$$

where $T_{P}$ is tolerance imposed on the drawing. For the quotes or conditions not specified in the plan of execution, the values of standards or norms must be adapted.

By imposing $\varepsilon_{o a}=\frac{1}{8} T_{P}$ are obtained the following allowable orientation errors:

$\mathrm{C}_{3}-\varepsilon_{o a}=\frac{1}{8} 0,4=0,05 \mathrm{~mm} ; \mathrm{C}_{11}-\varepsilon_{o a}=\frac{1}{8} 0,04=0,005 \mathrm{~mm}$;

$\mathrm{C}_{12}-\varepsilon_{o a}=\frac{1}{8} 0,6=0,075 \mathrm{~mm} ; \mathrm{C}_{14}-\varepsilon_{o a}=\frac{1}{8} 0,1=0,012 \mathrm{~mm}$

Real orientation errors $\left(\varepsilon_{o r}\right)$ are calculated as follows.

$\mathrm{V}_{\mathrm{I}}-(1)+(4)+(5)$

$$
\mathrm{C}_{3}-\varepsilon_{\text {or }}=\frac{T_{d}}{2 \sin \alpha / 2}=\frac{0,4}{2 \sin 45^{\circ}}=0,285 \mathrm{~mm} \text {. This value cannot be considered since during }
$$

the control operation in the orientation variant $V_{I}$, the surfaces of the part $\left(\mathrm{S}_{15}, \mathrm{~S}_{2}, \mathrm{~S}_{11}\right)$ come into contact with support elements of the control device which are identical to those on the drilling device and have an error of execution and installation of maximum 0.010 [mm].

In this case, the errors are:

$\mathrm{V}_{\mathrm{I}}-(1)+(4)+(5) ; \mathrm{C}_{3}-\varepsilon_{\text {or }}=0,010 \mathrm{~mm} ; \mathrm{C}_{11}-\varepsilon_{\text {or }}=0 ; \mathrm{C}_{12}-\varepsilon_{\text {or }}=0,010 \mathrm{~mm} ; \mathrm{C}_{14}-\varepsilon_{\text {or }}=0$

$\mathrm{V}_{\mathrm{II}}-(1)+(4)+(8) ; \mathrm{C}_{3}-\varepsilon_{\text {or }}=0,010 \mathrm{~mm} ; \mathrm{C}_{11}-\varepsilon_{\text {or }}=0 ; \mathrm{C}_{12}-\varepsilon_{\text {or }}=0 ; \mathrm{C}_{14}-\varepsilon_{\text {or }}=0$

$\mathrm{V}_{\mathrm{III}}-(2+3)+(4)+(5) ; \mathrm{C}_{3}-\varepsilon_{\text {or }}=0,148 \mathrm{~mm} ; \mathrm{C}_{11}-\varepsilon_{\text {or }}=0 ; \mathrm{C}_{12}-\varepsilon_{\text {or }}=0,010 \mathrm{~mm} ; \mathrm{C}_{14}-\varepsilon_{\text {or }}=0$

For $\mathrm{C}_{3}$ it is considered that element (3) is the same semi-prism of the element (1) and semi-prism (2) influences with half of the tolerance field of the surface:

$\mathrm{C}_{3}-\varepsilon_{\text {or }}=\frac{0,01+0,2}{1,414}=0,148 \mathrm{~mm}$

$\mathrm{V}_{\mathrm{IV}}-(2+3)+(4)+(8) ; \mathrm{C}_{3}-\varepsilon_{\text {or }}=0,148 \mathrm{~mm} ; \mathrm{C}_{11}-\varepsilon_{\text {or }}=0 ; \mathrm{C}_{12}-\varepsilon_{\text {or }}=0 ; \mathrm{C}_{14-\varepsilon_{\text {or }}}=0$

$\mathrm{V}_{\mathrm{V}}-(6+3)+(4)+(5) ; \mathrm{C}_{3}-\varepsilon_{\text {or }}=0,219 \mathrm{~mm} ; \mathrm{C}_{11}-\varepsilon_{\text {or }}=0 ; \mathrm{C}_{12}-\varepsilon_{\text {or }}=0,010 \mathrm{~mm} ; \mathrm{C}_{14}-\varepsilon_{\text {or }}=0$

For $\mathrm{C}_{3}$ it is considered that element (3) is the same semi-prism of element (1) and semiprism (6) influences with half of the tolerance field of the surface: 
$\mathrm{C}_{3}-\varepsilon_{\text {or }}=\frac{0,01+0,3}{1,414}=0,219 \mathrm{~mm}$

$\mathrm{V}_{\mathrm{VI}}-(6+3)+(4)+(8) ; \mathrm{C}_{3}-\varepsilon_{\text {or }}=0,219 \mathrm{~mm} ; \mathrm{C}_{11}-\varepsilon_{\text {or }}=0 ; \mathrm{C}_{12}-\varepsilon_{\text {or }}=0 ; \mathrm{C}_{14-} \varepsilon_{\text {or }}=0$

$\mathrm{V}_{\mathrm{VII}}-(7)+(4)+(5) ; \mathrm{C}_{3}-\varepsilon_{\text {or }}=0 ; \mathrm{C}_{11}-\varepsilon_{\text {or }}=0 ; \mathrm{C}_{12}-\varepsilon_{\text {or }}=0,010 \mathrm{~mm} ; \mathrm{C}_{14}-\varepsilon_{\text {or }}=0$

$\mathrm{V}_{\mathrm{VIII}}-(7)+(4)+(8) ; \mathrm{C}_{3}-\varepsilon_{\text {or }}=0 ; \mathrm{C}_{11}-\varepsilon_{\text {or }}=0 ; \mathrm{C}_{12}-\varepsilon_{\text {or }}=0 ; \mathrm{C}_{14}-\varepsilon_{\text {or }}=0$

The calculated values are written in Table 2 where the technically possible variants (VO-TP) matching relation $\varepsilon_{\text {or }}<\varepsilon_{\text {oa }}$ for all conditions $\mathrm{C}_{3} ; \mathrm{C}_{11} ; \mathrm{C}_{12} ; \mathrm{C}_{14}$ become technically acceptable orientation variants (VO-TA) and the others are removed as technically unacceptable orientation variants (VO-TNA).

Table 2. Synthesis of allowable and real orientation errors.

\begin{tabular}{|c|c|c|c|c|c|c|}
\hline \multirow{2}{*}{$\begin{array}{c}\text { Crt. } \\
\text { nb. }\end{array}$} & \multirow{2}{*}{ VO-TP } & $\mathrm{C}_{3} \varepsilon_{o a}=0,05 \mathrm{~mm}$ & $\mathrm{C}_{11} \varepsilon_{\rho a}=0,005 \mathrm{~mm}$ & $\mathbf{C}_{12} \varepsilon_{\text {oq }}=0,075 \mathrm{~mm}$ & $C_{14} \varepsilon_{o \alpha}=0,012 \mathrm{~mm}$ & VO-TA \\
\hline & & $\boldsymbol{\varepsilon}_{\boldsymbol{o r}}[\mathrm{mm}]$ & $\varepsilon_{o r}$ & $\boldsymbol{\varepsilon}_{\boldsymbol{o r}}[\mathrm{mm}]$ & $\varepsilon_{o r}$ & $\varepsilon_{o r}<\varepsilon_{o a}$ \\
\hline 1 & $\mathrm{~V}_{\mathrm{I}}$ & 0.010 & 0 & 0.010 & 0 & $\mathrm{X}(\mathrm{Yes})$ \\
\hline 2 & $\mathrm{~V}_{\mathrm{II}}$ & 0.010 & 0 & 0 & 0 & $\mathrm{X}(\mathrm{Yes})$ \\
\hline 3 & $\mathrm{~V}_{\text {III }}$ & 0.148 & 0 & 0.010 & 0 & - \\
\hline 4 & $\mathrm{~V}_{\text {IV }}$ & 0.148 & 0 & 0 & 0 & - \\
\hline 5 & $\mathrm{~V}_{\mathrm{V}}$ & 0.219 & 0 & 0.010 & 0 & - \\
\hline 6 & $\mathrm{~V}_{\mathrm{VI}}$ & 0.219 & 0 & 0 & 0 & - \\
\hline 7 & $\mathrm{~V}_{\mathrm{VII}}$ & 0 & 0 & 0.010 & 0 & $\mathrm{X}(\mathrm{Yes})$ \\
\hline 8 & $\mathrm{~V}_{\mathrm{VIII}}$ & 0 & 0 & 0 & 0 & $\mathrm{X}(\mathrm{Yes})$ \\
\hline
\end{tabular}

\section{E08 The economic analysis VO-TA}

In Table 3 the economic optimization obtained by the method of utilities proposed in paper $[1-3,7]$ allows establishing optimal orientation elements under the form of optimal orientation scheme (SO-O) based on coefficients of importance assigned to the orientation elements for the six economic criteria analyzed $\left(\mathrm{CE}_{1} \ldots \mathrm{CE}_{6}\right)$.

$\mathrm{CE}_{1}$ - number of elements composing the support symbolized;

$\mathrm{CE}_{2}$ - complexity of elements;

$\mathrm{CE}_{3}$ - cost of constructive elements associated to the informational symbolization;

$\mathrm{CE}_{4}$ - productivity concerning the convenient use of the device;

Table 3. Economic optimization by the method of utilities.

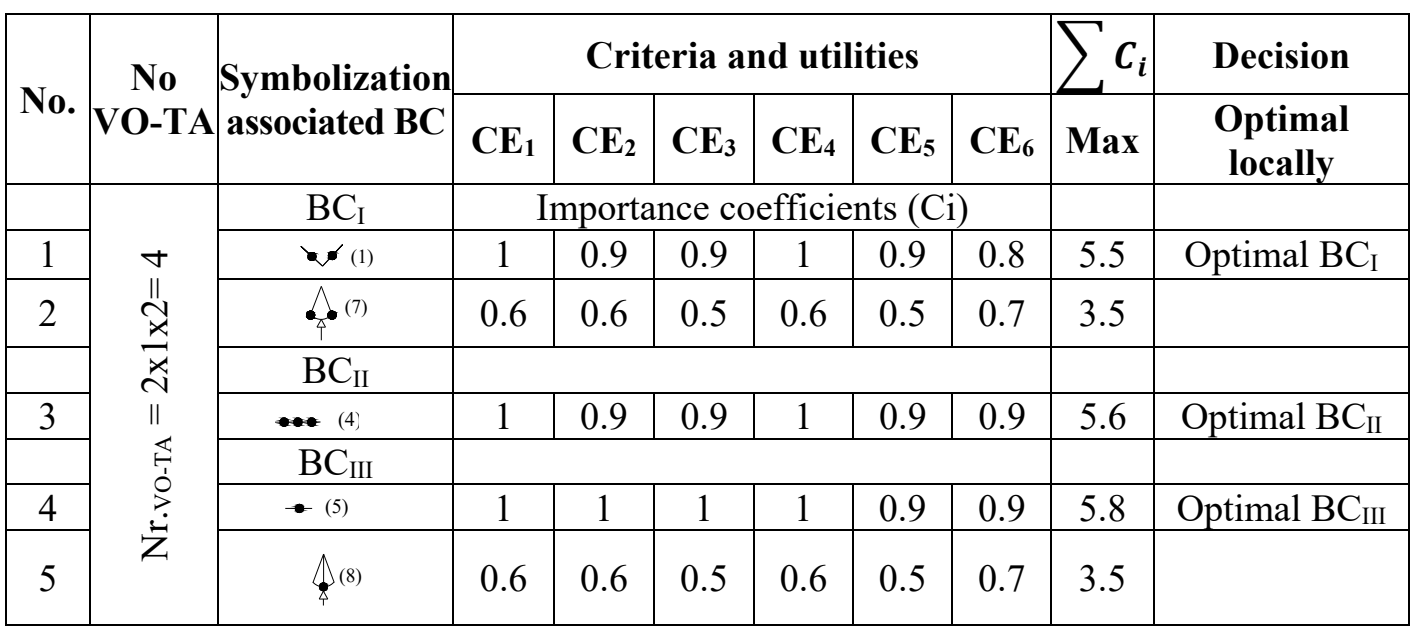

$\mathrm{CE}_{5}$ - wear and cost of maintenance (exploitation);

$\mathrm{CE}_{6}$ - reuse of support elements for the construction of other elements. 
The optimal orientation scheme ( $\mathrm{SO}-\mathrm{O})$ is:

$$
\mathrm{SO}-\mathrm{O}=\bullet \cdot(1)+\bullet \bullet(4)+\bullet(5)
$$

\section{E09 Choice of the fixing system}

A secondary adjustment force of the support with self-place and lock (9) brings the part that sits on the flat base of pre-orientation (11) into contact with the first short line (1) and support plate 5 (see Fig.2). The main flat base (4) flips in working position to bring the part under the action of the support (12) with self-place and lock, which originally has the function of a main adjustment force, afterwards becoming a fixing force.

For the measurements, the three special supports (10), with auto-position and blocking further come into contact with the part and define a flat substitute base, which preserves the original orientation of the part and accuracy of the operation, and then the flat base (4) flips.

The optimal orientation and fixing scheme is:

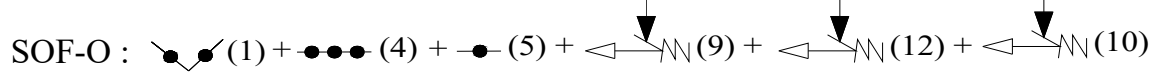

\section{Conclusions}

In the activity of research-design and realization of industrial applications it is necessary to have a well-reasoned multi-criteria approach of the problems analysed, leading to objective decisions and rational solutions to build devices and technological equipment. The systemic approach on issues to optimize processes and technological equipment is determined by the need to highlight the multitude of factors influencing it and their interdependency in order to establish rational solutions in the field of industrial engineering.

In this paper the original contribution of the authors refers to a mathematical model and a new method to optimize the orientation and fixing scheme of workpieces to build work and control devices. Based on this methodology, there was obtained a solution of a technological device as industrial application, with clear new elements from a kinematic, technological, structural and functional point of view, which is the subject of a patent.

\section{References}

1. A. Brăgaru, Proiectarea dispozitivelor. Teoria şi practica proiectării schemelor de orientare şi fixare, 1, (Ed. Tehn. Bucureşti, 1998).

2. D. M. Iordache, A. Costea, Al. Babă, Metode de calcul şi modele matematice pentru optimizarea proiectării dispozitivelor (Ed. Univ. din Piteşti, 2016).

3. N.V. Ivan, T. Păunescu, R. Udroiu, M.C. Ivan, C. Găvruş, R. Pescaru, Tehnologia Construcţiilor de Maşini - Teorie şi abordări inovative, I, (Ed. Univ. Transilvania din Braşov, 2010).

4. G. H. Qin, W.H. Zhang, Int. J. Adv. Manuf. Tech., 29,(2006).

5. A. Sturzu, Bazele proiectării dispozitivelor de control al formei şi poziției relative a suprafețelor în construcția de mașini. (Ed. Tehn. Bucureşti,1977).

6. J.J.X. Liu, D.R. StrongInt. J. Adv. Manuf. Tech., 21, (2003).

7. T. Păunescu, H. Bulea, R. Păunescu, Dispozitive modulare, II, (Ed. Univ. Transilvania din Braşov, 2008).

8. B. Li. Int. J. Adv. Manuf. Tech.,17, (2001)

9. A. Raghu, S.N. Melkote, Procedings of IMECE'03 2003 ASME International Mechanical Engineering Congress \& Exposition Wasington, D.C., (2003). 